\title{
QUALIDADE DE OVOS E DESEMPENHO PRODUTIVO DE POEDEIRAS EM SEGUNDO CICLO DE POSTURA ALIMENTADAS COM MICROMINERAIS QUELATADOS A AMINOÁCIDOS
}

\author{
EGG QUALITY AND PRODUCTIVE PERFORMANCE OF LAYING HENS \\ IN SECOND CYCLE OF POSTURE FED WITH AMINOACID CHELATED \\ TRACE MINERALS
}

\author{
Leticia Souza Silva Carvalho ${ }^{1 *}$ \\ Daniela Reis Vilela ${ }^{1}$ \\ Naiara Simarro Fagundes ${ }^{1}$ \\ Yara Lucia Silva Souza ${ }^{1}$ \\ Evandro de Abreu Fernandes ${ }^{1}$
}

${ }^{1}$ Universidade Federal de Uberlândia, Uberlândia, MG, Brasil.

*Autora para correspondência - leticiasouzavet@hotmail.com

\begin{abstract}
Resumo
Objetivou-se com esta pesquisa avaliar o desempenho produtivo e a qualidade de ovos de poedeiras em segundo ciclo de postura alimentadas com microminerais de fonte orgânica. $\mathrm{O}$ tratamento controle foi composto por dieta basal e microminerais inorgânicos e os demais tratamentos consistiram da inclusão dos microminerais cobre, ferro, manganês e zinco orgânicos, em substituição total à fonte inorgânica, em níveis de $100 \%, 90 \%, 80 \%$ e 70\%. Análises físicas e bromatológicas foram realizadas para avaliar a qualidade dos ovos. O peso médio dos ovos diminuiu nas dietas teste; no entanto, a massa de ovos bem como as demais variáveis de desempenho avaliadas não sofreram influencia dos tratamentos. O percentual de proteína do ovo diminuiu; entretanto, a matéria mineral do conteúdo interno e casca aumentaram com o uso de minerais orgânicos, assim como houve melhora nos parâmetros de qualidade da casca. A suplementação de microminerais de fonte orgânica a dieta das poedeiras não comprometeu a qualidade interna dos ovos. A total substituição da fonte inorgânica por níveis de minerais orgânicos nas dietas das aves proporcionou manutenção no desempenho zootécnico e melhorias na qualidade de casca.
\end{abstract}

Palavras-chave: minerais quelatados; produção de ovos; qualidade de casca.

\begin{abstract}
The goal of this research was to evaluate egg quality and performance of laying hens at the second laying cycle, fed with minerals from an organic source. The control treatment consisted of basal diet with inorganic trace minerals, whereas the other treatments consisted of organic copper, iron, manganese, and zinc at levels of $100 \%, 90 \%, 80 \%$, and $70 \%$. Physical and chemical analyses were performed to evaluate egg quality. The average egg weight reduced in the test diet; however, egg mass, as well as the other performance variables evaluated, did not suffer influence of treatments. The percentage of egg protein decreased; however, mineral matter content and egg shell increased with the use of organic minerals, as well as an improvement in the egg quality parameters occurred. The supplementation with organic trace mineral source of the diet of laying hens did not compromise internal egg quality. The total replacement of inorganic sources for levels of organic minerals in the diet of birds provided maintenance on the performance and improved shell quality.
\end{abstract}

Keywords: chelated minerals; egg production; eggshell quality. 
Enviado em: 26 outubro 2012

Aceito em: 01 setembro 2016

\section{Introdução}

A nutrição adequada exerce importante influencia sobre a saúde e desempenho produtivo dos animais. Nesse sentido, a suplementação de microminerais tem ganhado especial atenção entre pesquisadores e produtores. Os microminerais são elementos essenciais a vários processos bioquímicos fundamentais ao crescimento, desenvolvimento, formação óssea e produção e, portanto, relacionam-se de forma direta ou indireta com a formação e qualidade de ovos ${ }^{(1)}$.

Os microminerais são normalmente suplementados na dieta das aves em sua forma inorgânica; contudo, sua biodisponibilidade pode ser prejudicada por variações de $\mathrm{pH}$ que ocorrem ao longo do trato digestório da ave e que favorecem a ocorrência de antagonismos e interações dos metais entre si e com outros compostos que se associam procurando estabilizar sua molécula, formando, assim, compostos insolúveis, incapazes de ser absorvidos pela ave ${ }^{(2)}$. Para melhorar sua disponibilidade biológica, os minerais têm sido associados a compostos orgânicos que dão maior estabilidade e solubilidade à molécula facilitando, assim, sua absorção pelo organismo e proporcionando melhorias na vida útil da ave.

O manganês e o zinco são cofatores de metaloenzimas envolvidas na síntese de mucopolissacarídeos e carbonato que compõem a matriz orgânica da casca, sendo fundamentais para a formação da mesma $^{(3)}$. O cobre está envolvido no metabolismo do ferro e oxigênio, síntese de colágeno e elastina, é integrante de proteínas do sangue, importante na formação de $\operatorname{ossos}^{(4)}$, desenvolvimento e coloração de penas $^{(5)}$. Apesar de seu papel na formação da casca ainda não estar completamente definido, a deficiência de cobre resulta em alterações no tamanho, forma e textura da casca e alta incidência de ovos de casca fina ${ }^{(6)}$. O ferro é constituinte de hemoglobina e mioglobina envolvidas na oxidação, redução e transporte de elétrons, indispensável aos processos vitais do organismo ${ }^{(7)}$.

Objetivou-se com esta pesquisa avaliar o desempenho produtivo e a qualidade de ovos de poedeiras em segundo ciclo de postura alimentadas com dietas contendo os microminerais cobre, ferro, manganês e zinco de fonte orgânica adicionados às dietas em níveis de inclusão.

\section{Material e Métodos}

A pesquisa foi conduzida na Granja Experimental da Fazenda do Glória da Universidade Federal de Uberlândia (UFU), no município de Uberlândia, Minas Gerais, onde foram alojadas 250 poedeiras da linhagem Dekalb White, em segundo ciclo de produção, com 100 semanas de idade.

O galpão experimental utilizado era aberto, com cobertura de telhas de fibrocimento, piso concretado, equipado com duas fileiras de gaiolas de arame galvanizado, medindo 1,00 m de comprimento, 0,50 $\mathrm{m}$ de largura e 0,40 $\mathrm{m}$ de altura divididas ao meio. Cada gaiola alojou dez aves, sendo cinco em cada divisória. As aves foram distribuídas de forma aleatória nas unidades experimentais. Cada conjunto contendo dez aves compôs uma unidade experimental. As gaiolas foram equipadas com um bebedouro tipo nipple e comedouro linear em frente à gaiola.

No período do estudo, foi mantido diariamente um programa de iluminação de 17 horas de luz, entre natural e artificial. Cada ave consumiu em média 106 gramas de ração diariamente e água foi fornecida ad libitum. Foi realizado um delineamento inteiramente casualizado com cinco tratamentos e cinco repetições. As dietas isoenergéticas e isonutrientes foram formuladas e produzidas à base de sorgo e farelo de soja (Tabela 1). 
Tabela 1. Niveis nutricionais da deita basal (controle) e niveis de inclusão dos microminerais cobre, ferro, manganês e zinco nas dietas experimentais

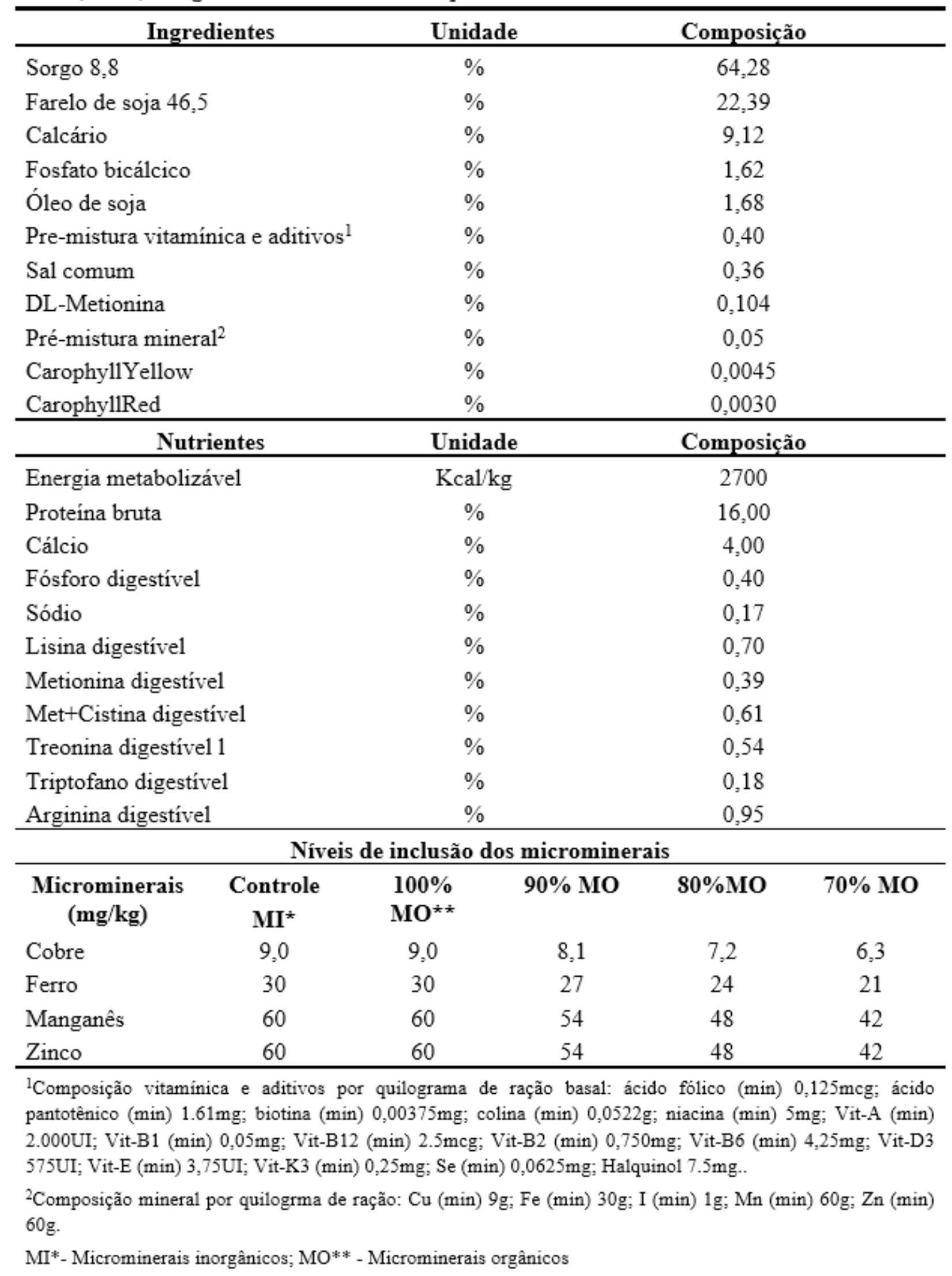


O tratamento controle foi composto da inclusão dos elementos cobre, ferro, manganês e zinco sobre a forma de sais (sulfato de cobre, sulfato de ferro, monóxido de manganês e óxido de zinco, respectivamente). Os demais tratamentos consistiram de inclusão na dieta basal de mistura dos microminerais orgânicos cobre, ferro, manganês e zinco (Tabela 1) em substituição total aos microminerais inorgânicos, nas concentrações de 100\%, 90\%, 80\% e 70\% dos níveis de inclusão dos minerais de fonte inorgânica.

A duração do experimento foi de 49 dias, destes 14 dias foram reservados à adaptação das aves ao manejo experimental. Para avaliação da produção, determinou-se o percentual médio de produção de ovos em relação ao número total de aves. A conversão alimentar foi determinada pelo cálculo da quantidade de ração consumida para se produzir uma dúzia de ovos. Para o peso médio dos ovos, todos os ovos íntegros foram pesados e seu valor dividido pelo número total de ovos. A massa de ovos foi calculada multiplicando-se o peso médio dos ovos pelo percentual de produção e dividindo-se por cem. Para a avaliação da qualidade de casca, determinou-se para cada tratamento o percentual de ovos trincados no útero, em relação aos ovos normais, pela observação de trincas internas na casca do ovo por meio de foco de luz em ambiente escuro (ovoscopia). Além de percentual de ovos quebrados e trincados em relação ao número total de ovos e gravidade específica dos ovos pelo método de imersão em cinco soluções salinas em diferentes densidades (1070, 1075, 1080, 1085 e 1090), como proposto por Hamilton ${ }^{(8)}$.

Ao final do período experimental, foram tomados ao acaso 30 ovos de cada tratamento, sendo seis ovos de cada repetição. Eles foram individualmente identificados e pesados em balança digital com escala de precisão de meio grama. Os ovos foram seccionados no sentido transversal; em seguida, foram pesados separadamente albúmen, gema e casca para determinação de suas respectivas percentagens em relação ao peso do ovo íntegro.

Os albumens e gemas dos seis ovos, de cada repetição, respectivamente, foram agrupados com o objetivo de formar uma amostra, totalizando cinco amostras compostas por tratamento, para a realização das análises bromatológicas. As amostras foram homogeneizadas para determinação do $\mathrm{pH}$ por meio do potenciômetro digital marca Gehaka. Em seguida, foram dispostas na estufa de circulação forçada a $55^{\circ} \mathrm{C}$ por 72 horas para a determinação da matéria seca e, por diferença, a umidade. Ainda foram determinadas matéria mineral, proteína bruta (método de Kjeldahl) e extrato etéreo (Extrato Soxhlet), este último somente para gema.

Após higienização em água corrente, as cascas tiveram as membranas removidas e, após secagem, tiveram sua face interna corada com solução de azul de metileno $(1 \mathrm{~g} / 100 \mathrm{~mL}$ de etanol a $70 \%)$ para que a cor azul se difundisse através dos poros facilitando a visualização dos mesmos na face externa. Em seguida, foram feitas marcações na face externa das cascas de $1 \times 1 \mathrm{~cm}^{2}$ nos pólos maior, menor e meio do ovo, e com o auxílio de uma lupa procedeu-se à contagem visual dos poros conforme metodologia de Peebles e Brake ${ }^{(9)}$. Utilizando-se de um micrômetro digital, marca Mitutoyo, mediuse a espessura das cascas nos pólos maior, menor e meio do ovo e seus valores foram expressos em milímetros (mm).

Para determinação da matéria mineral, as seis cascas de cada repetição foram agrupadas a fim de formar uma amostra, trituradas em moinho convencional (Elo) e peneiradas em tela de dois milímetros, pesadas e colocadas em Mufla. O percentual de cálcio e fósforo contidos nas cascas foi determinado pelos métodos de oxidimetria e colorimétrico, respectivamente.

Após verificação da homogeneidade das variâncias e a normalidades dos resíduos, as variáveis estudadas foram submetidas à análise de variância e comparação de médias pelo teste de Dunnett 5\% e análise de regressão (linear e quadrática) entre os níveis.

\section{Resultados}

O peso médio dos ovos reduziu quando foram adicionados $70 \%$ e $80 \%$ de microminerais orgânicos à dieta; no entanto, as demais variáveis de desempenho avaliadas não diferiram estatisticamente entre os tratamentos (Tabela 2). 
Tabela 2. Peso médio dos ovos (g), percentual de produção semanal (\% ovos produzidos/ave/semana), massa de ovos (g), conversão alimentar (kg ração/dúzia de ovos produzidos) de poedeiras em segundo ciclo de produção alimentadas com dietas contendo microminerais inorgânicos e níveis de inclusão de microminerais orgânicos

\begin{tabular}{|c|c|c|c|c|}
\hline \multicolumn{5}{|c|}{ Desempenho Produtivo } \\
\hline Tratamentos & Peso Médio & $\begin{array}{l}\text { Produção } \\
\text { Semanal }\end{array}$ & $\begin{array}{c}\text { Massa de } \\
\text { Ovos }\end{array}$ & Conversão Alimentar \\
\hline Controle $\mathrm{MI}^{\mathrm{a}}$ & 72,13 & 80,52 & 58,07 & 1,614 \\
\hline $100 \% \mathrm{MO}^{\mathrm{b}}$ & 70,07 & 85,11 & 59,63 & 1,512 \\
\hline $90 \%$ MO & 72,48 & 84,02 & 60,90 & 1,534 \\
\hline $80 \%$ MO & $69,05 *$ & 83,96 & 57,95 & 1,544 \\
\hline $70 \%$ MO & $69,14^{*}$ & 82,10 & 56,76 & 1,569 \\
\hline $\mathrm{CV}^{\mathrm{c}}(\%)$ & 2,32 & 4,63 & 2,22 & 4,61 \\
\hline Regressão & NS & NS & NS & NS \\
\hline
\end{tabular}

O percentual de ovos trincados no útero, a gravidade específica e o percentual de ovos trincados/ quebrados não sofreram influencia dos tratamentos (Tabela 3 ).

Tabela 3. Percentual de ovos trincados no útero (\%), gravidade específica $(\mathrm{g} / \mathrm{mL})$ e percentual de ovos trincados e quebrados de poedeiras em segundo ciclo de produção alimentadas com dietas contendo microminerais inorgânicos e níveis de inclusão de microminerais orgânicos

\begin{tabular}{lccc}
\hline & \multicolumn{3}{c}{ Qualidade de Casca } \\
\cline { 2 - 4 } Tratamentos & Trincados no Útero & Gravidade Específica & Quebrados/trincados \\
\hline Controle MI $^{\mathbf{a}}$ & 28,92 & 1081,66 & 1,95 \\
$\mathbf{1 0 0 \%} \mathbf{M O}^{\mathbf{b}}$ & 35,97 & 1081,95 & 1,40 \\
$\mathbf{9 0 \%}$ MO & 38,87 & 1082,06 & 2,01 \\
$\mathbf{8 0} \%$ MO & 34,87 & 1082,26 & 1,81 \\
$\mathbf{7 0} \%$ MO & 37,43 & 1082,43 & 1,92 \\
\hline CVc (\%) & 18,45 & 0,13 & 63,83 \\
Regressão & $\mathrm{NS}$ & $\mathrm{NS}$ & $\mathrm{NS}$ \\
\hline MI & Micromineral inorgânico; MO & Micromineral orgânico; CVc - Coeficiente de Variação, NS - não \\
significativo. Teste de Dunnett $5 \%(\mathrm{P}<0,05)$. &
\end{tabular}

O percentual de albúmen, umidade e pH não sofreram influência dos tratamentos, enquanto a proteína bruta reduziu nos ovos produzidos por aves alimentadas com dieta contento microminerais de fonte orgânica. A matéria mineral mostrou-se maior nos tratamentos com inclusão de $90 \%$ e $70 \%$ de inclusão de microminerais orgânicos (Tabela 4). 
Tabela 4. Percentual albúmen, umidade, proteína bruta, matéria mineral e valores de $\mathrm{pH}$ de albúmen de ovos de poedeiras em segundo ciclo de produção alimentadas com dietas contendo microminerais inorgânicos e níveis de inclusão de microminerais orgânicos

\begin{tabular}{|c|c|c|c|c|c|}
\hline Tratamentos & $\begin{array}{c}\text { Albúmen } \\
(\%)\end{array}$ & $\begin{array}{c}\text { Umidade } \\
(\%)\end{array}$ & $\begin{array}{c}\text { Proteína Bruta } \\
(\%)\end{array}$ & $\begin{array}{c}\text { Matéria } \\
\text { Mineral } \\
(\%)\end{array}$ & $\mathrm{pH}$ \\
\hline Controle MI* & 58,43 & 89,05 & 9,42 & $0,46 \mathrm{~b}$ & 8,05 \\
\hline $100 \% \mathrm{MO}^{* *}$ & 58,39 & 88,71 & $8,67^{*}$ & $0,48 \mathrm{~b}$ & 8,10 \\
\hline $90 \%$ MO & 57,69 & 88,70 & $8,50^{*}$ & $0,54^{*}$ & 8,08 \\
\hline $80 \%$ MO & 57,03 & 89,01 & $8,60 *$ & 0,45 & 8,07 \\
\hline $70 \% \mathrm{MO}$ & 57,14 & 88,76 & $8,54^{*}$ & $0,55^{*}$ & 8,10 \\
\hline $\mathrm{CV}^{\mathrm{c}}(\%)$ & 2,14 & 0,42 & 2,27 & 6,47 & 0,62 \\
\hline Regressão & NS & NS & NS & NS & NS \\
\hline
\end{tabular}

$\mathrm{MI}^{\mathrm{a}}$ - Micromineral inorgânico; $\mathrm{MO}^{\mathrm{b}}$ - Micromineral orgânico; $\mathrm{CV}^{\mathrm{c}}-$ Coeficiente de Variação. NS - não significativo. *Médias diferem do controle pelo teste de Dunnett $5 \%(\mathrm{P}<0,05)$.

O percentual de gema e $\mathrm{pH}$ não diferiu estatisticamente entre os tratamentos. No entanto, no percentual de umidade nos níveis $70 \%$ e $80 \%$ de microminerais de fonte orgânica, observou-se redução significativa em relação ao controle. A proteína bruta reduziu de forma quadrática nos tratamentos com inclusão de orgânicos, ficando estes estatisticamente inferiores ao percentual do tratamento controle. Observou-se aumento de matéria mineral nos ovos oriundos de aves alimentadas com dietas testes, exceto no tratamento $80 \%$ de inclusão de microminerais orgânicos, que foi estatisticamente igual ao tratamento controle. $\mathrm{O}$ extrato etéreo variou quadraticamente entre os tratamentos sem, no entanto, diferir do tratamento controle (Tabela 5).

Tabela 5. Percentual de gema, umidade, proteína bruta, matéria mineral $\mathrm{pH}$ e extrato etéreo de ovos de poedeiras em segundo ciclo de postura, alimentadas com dietas contendo microminerais inorgânicos e níveis de inclusão de microminerais orgânicos

\begin{tabular}{|c|c|c|c|c|c|c|}
\hline Tratamentos & $\begin{array}{c}\text { Gema } \\
(\%)\end{array}$ & $\begin{array}{c}\text { Umidade } \\
(\%)\end{array}$ & $\begin{array}{c}\text { Proteína } \\
\text { Bruta (\%) }\end{array}$ & $\begin{array}{c}\text { Matéria } \\
\text { Mineral } \\
(\%)\end{array}$ & $\mathbf{p H}$ & $\begin{array}{c}\text { Extrato } \\
\text { Etéreo (\%) }\end{array}$ \\
\hline Controle MI* & 25,62 & 50,88 & 17,70 & 1,58 & 5,96 & 32,47 \\
\hline $100 \% \mathrm{MO}^{* *}$ & 25,08 & 49,81 & $16,63^{*}$ & $1,72^{*}$ & 5,99 & 31,97 \\
\hline $90 \% \mathrm{MO}$ & 25,73 & 49,54 & $17,09^{*}$ & $1,76^{*}$ & 6,00 & 32,39 \\
\hline $\mathbf{8 0} \% \mathrm{MO}$ & 25,89 & $48,96^{*}$ & $16,97^{*}$ & 1,65 & 6,01 & 32,44 \\
\hline $70 \% \mathrm{MO}$ & 26,26 & $48,41^{*}$ & $16,81^{*}$ & $1,70^{*}$ & 6,03 & 31,82 \\
\hline $\mathrm{CV}^{\mathrm{c}}(\%)$ & 3,54 & 1,71 & 1,53 & 3,78 & 0,75 & 1,50 \\
\hline Regressão & NS & Linear $^{1}$ & Quadrática $^{2}$ & NS & NS & Quadrática $^{3}$ \\
\hline \multicolumn{7}{|c|}{$\begin{array}{l}\mathrm{MI}^{\mathrm{a}} \text { - Micromineral inorgânico; } \mathrm{MO}^{\mathrm{b}}-\text { Micromineral orgânico; } \mathrm{CV}^{\mathrm{c}}-\text { Coeficiente de Variação. NS - não } \\
\text { significativo. *Médias diferem do controle pelo teste de Dunnett } 5 \%(\mathrm{P}<0,05) \text {. }\end{array}$} \\
\hline$y=45,1128-0,04782$ & $R^{2}=0,5156$ & & & & & \\
\hline
\end{tabular}


O percentual de casca foi estatisticamente igual em todos os tratamentos (Tabela 6); todavia, observouse aumento de forma linear e quadrática, respectivamente, no percentual de matéria mineral e cálcio nas cascas dos ovos dos tratamentos $90 \%, 80 \%$ e 70\% de fonte orgânica, ficando seus valores superiores ao tratamento controle. Os ovos das dietas contendo microminerais orgânicos apresentaram menor quantidade de poros por centímetro quadrado em relação à casca de ovos do grupo controle, em que se observou efeito quadrático desta variável. Além disso, o tratamento contendo os mesmos níveis de inclusão do tratamento controle produziu cascas de ovos significativamente mais espessas que os demais tratamentos, em que comportamento quadrático foi novamente observado (Tabela 6).

Tabela 6. Percentual de casca, matéria mineral, cálcio, fósforo, número de poros por centímetro quadrado (poros $/ \mathrm{cm}^{2}$ ), espessura em milímetros $(\mathrm{mm})$ de casca ovos de poedeiras em segundo ciclo de produção alimentadas com dietas contendo microminerais inorgânicos e diferentes níveis de inclusão de microminerais orgânicos

\begin{tabular}{|c|c|c|c|c|c|c|}
\hline Tratamentos & $\begin{array}{c}\text { Casca } \\
(\%)\end{array}$ & $\begin{array}{c}\text { Matéria } \\
\text { Mineral } \\
(\%)\end{array}$ & Cálcio (\%) & $\begin{array}{c}\text { Fósforo } \\
(\%)\end{array}$ & $\begin{array}{c}\text { Poros } \\
\left(\text { poros } / \mathrm{cm}^{2}\right)\end{array}$ & $\begin{array}{c}\text { Espessura } \\
\text { (mm) }\end{array}$ \\
\hline Controle MI & 13,68 & 94,34 & 43,49 & 0,52 & 127,19 & 0,368 \\
\hline $100 \% \mathrm{MO}$ & 13,37 & 94,56 & 43,49 & 0,51 & $120,40 *$ & $0,371^{*}$ \\
\hline $90 \% \mathrm{MO}$ & 13,37 & $95,14^{*}$ & $45,49 *$ & $0,49 *$ & $122,98^{*}$ & 0,368 \\
\hline $80 \%$ MO & 13,79 & $95,30 *$ & $45,29 *$ & $0,48^{*}$ & $122,88^{*}$ & 0,367 \\
\hline $70 \% \mathrm{MO}$ & 13,65 & $95,39 *$ & $46,65^{*}$ & 0,50 & $123,01^{*}$ & 0,367 \\
\hline $\mathrm{CV}^{\mathrm{c}}(\%)$ & 4,10 & 0,38 & 0,67 & 2,63 & 0,62 & 0,37 \\
\hline
\end{tabular}

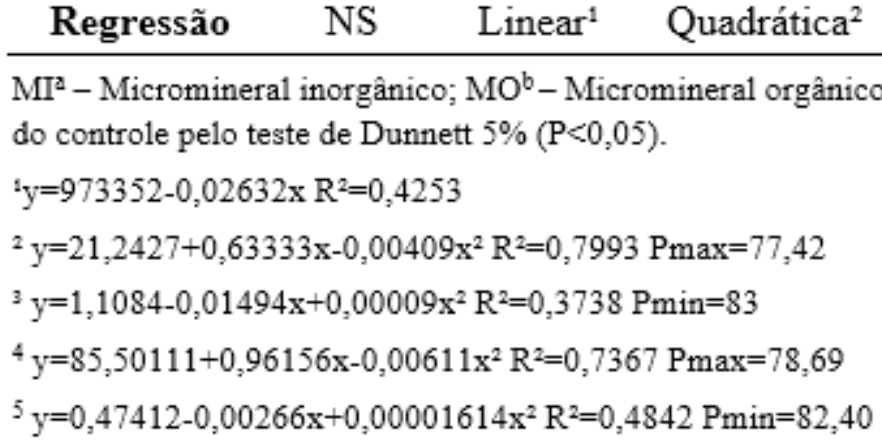

\section{Discussão}

O peso dos ovos de aves alimentadas com microminerais orgânicos apresentou tendência de diminuição ( $80 \%$ e $70 \% \mathrm{MO})$; no entanto, a massa de ovos não diferiu entre os tratamentos. Amaior biodisponibilidade dos minerais quelatados proporcionou manutenção das demais variáveis de desempenho avaliadas.

Assim como no presente trabalho, Fernandes et al. ${ }^{(10)}$ também observaram redução no peso médio de ovos quando utilizaram uma mistura de $250 \mathrm{ppm}$ de zinco, manganês e selênio orgânicos. Todavia, não verificaram diferença estatística para a massa de ovos. Isto se justificou porque o percentual de produção de ovos não diferiu estatisticamente entre os tratamentos. Os autores também não verificaram diferenças na gravidade específica dos ovos e o percentual de ovos quebrados e trincados.

Em pesquisa sobre suplementação de poedeiras em diferentes idades, com os microminerais zinco, manganês e cobre orgânicos, Mabe et al. ${ }^{(2)}$ também observaram diminuição no peso dos ovos quando as aves que os produziram eram mais velhas. No entanto, os autores não encontraram qualquer relação entre o nível de suplementação de minerais quelatados e os efeitos sobre o peso dos ovos, além do 
efeito negativo sobre o peso dos ovos não vir acompanhado por alterações significativas sobre os parâmetros de qualidade da casca. Resultado semelhante ao encontrado no presente trabalho, em que o peso dos ovos não provocou alterações na gravidade específica, percentual de ovos trincados no útero e percentual de ovos quebrados e trincados.

Observou-se aumento no percentual de matéria mineral em albúmen (90\% e 70\% MO), gema (100\%, $90 \%$ e $70 \%$ ) e casca $(90 \%, 80 \%$ e $70 \%)$, indicando que a inclusão de microminerais de fonte orgânica às dietas das poedeiras favoreceu a deposição mineral nesses componentes dos ovos, mesmo quando o nível de inclusão foi de $70 \%$, o que aponta para maior biodisponibilidade dos microminerais de fonte orgânica em relação à fonte inorgânica. Isso possivelmente ocorreu porque os microminerais orgânicos se utilizam de vias de absorção das moléculas orgânicas às quais estão ligados, favorecendo sua absorção por evitar a competição dos microminerais pelo mesmo transportador, tornando-os mais prontamente transportáveis e absorvíveis para utilização pelo organismo ${ }^{(11)}$, mesmo em níveis de suplementação inferiores aos comumente praticados em granjas comerciais. Esses achados corroboram os relatos de Dobrzanskiet al al. ${ }^{(12)}$, que indicaram a possibilidade de enriquecimento mineral de ovos com o fornecimento de micromineral orgânico na dieta das poedeiras.

A redução no percentual total de proteína dos ovos produzidos por poedeiras que consumiram dietas contendo microminerais orgânicos variou de 5,72\% a 7,34\%. Nenhum relato foi encontrado na literatura sobre a redução no teor protéico dos ovos quando as poedeiras foram suplementadas com essa fonte de microminerais. Possivelmente porque grande parte dos trabalhos não avalia o percentual dos principais nutrientes dos ovos, sendo a avaliação da qualidade mensurada através de outros parâmetros. Saldanha et al. ${ }^{(13)}$ fizeram menção ao teor de proteína da gema de ovos de poedeiras de segundo ciclo de postura em pesquisa com delineamento semelhante; entretanto, não observaram diferença significativa no conteúdo de proteína, percentual e composição mineral da gema de ovos. Os autores não apresentaram resultado para o percentual de proteína do albúmen.

Apesar de a fonte orgânica de microminerais utilizada ser quelatada a proteínas parcialmente hidrolisadas e aminoácidos, isso não poderia determinar qualquer influência sobre o teor proteico dos ovos, porque, na formulação desses compostos, utiliza-se pequena quantidade de molécula orgânica no processo de quelação. Além disso, a quantidade de microminerais utilizada na suplementação das dietas foi pequena; portanto, o teor proteico desse ingrediente não seria capaz de interferir na absorção de proteínas dos demais componentes da dieta e na sua utilização no metabolismo da poedeira e na deposição proteica dos ovos.

Embora tenha havido diminuição significativa no percentual de proteína bruta de albúmen e gema de ovos produzidos por aves alimentadas com níveis de inclusão de microminerais orgânicos, esta redução não foi acentuada, não comprometendo, assim, a qualidade nutricional do ovo, considerado um alimento nutricionalmente completo e fornecedor de proteínas de alto valor biológico.

Apesar de o percentual de casca nos ovos da presente pesquisa não ter diferido do controle, o aumento na proporção da matéria mineral e cálcio $(90 \%, 80 \%, 70 \% \mathrm{MO})$, além de redução no número de poros $(100 \%, 90 \%, 80 \%$ e $70 \%$ MO) quando a suplementação orgânica foi realizada, indica influencia positiva sobre os parâmetros de qualidade de casca e sinaliza para maior biodisponibilidade em relação à fonte inorgânica.

Os microminerais são capazes de afetar a qualidade da casca por serem componentes essenciais de enzimas que apresentam propriedades catalíticas envolvidas na síntese de membranas e casca do ovo ou pela interação direta com cristais de cálcio durante o processo de formação da casca ${ }^{(14)}$. Mabe et al. ${ }^{(2)}$ sugeriram que a suplementação de poedeiras com microminerais traços pode influenciar diretamente a formação do carbonato de cálcio, e consequentemente, a textura da casca. Para esses autores, os microminerais promovem fusão precoce durante a fase inicial da formação da casca, o que melhora sua resistência mecânica independentemente de sua espessura.

Sabendo que a inclusão de minerais inorgânicos na dieta de poedeiras comerciais é normalmente realizada em nível superior às exigências das poedeiras e, considerando que os maiores níveis de inclusão de minerais do presente trabalho foram efetuadas tendo por base esses valores, pode se inferir que o excesso de inclusão desses nutrientes pode ter provocado interações ou antagonismo entre si e outros compostos. Isso se deve ao fato de que as dietas contendo maior nível de inclusão de microminerais 
orgânicos e aquela com microminerais inorgânicos proporcionaram casca de ovos com menor conteúdo de matéria mineral e cálcio em comparação aos tratamentos com menores níveis de inclusão de fonte orgânica.

No presente trabalho, a inclusão de microminerais foi efetuada tendo por base os níveis comumente aplicados nas granjas comerciais. $\mathrm{O}$ aumento do percentual de matéria mineral e cálcio aliada à redução no percentual de fósforo, diminuição do número de poros e manutenção de espessura de casca nos níveis de inclusão de $70 \%, 80 \%$ e $90 \% \mathrm{MO}$, quando comparados ao tratamento controle, indicam maior biodisponibilidade dos microminerais de fonte orgânica. Ao mesmo tempo, apontam para um excesso de inclusão de microminerais praticados atualmente, já que o maior nível de inclusão de fonte orgânica apresentou níveis de matéria mineral, cálcio e fósforo equivalentes aos das cascas do tratamento controle e não resultados superiores a ele como era de se esperar. O que deixa claro que há um excesso de suplementação de microminerais na dieta das poedeiras praticada nas granjas comerciais.

Para Fernandes et al.(10), a inclusão de minerais em níveis superiores às reais exigências dos animais dificulta a detecção de quaisquer benefícios adicionais da suplementação de minerais traços, independente da apresentação na forma orgânica ou inorgânica.

Os resultados da presente pesquisa apontam para maior biodisponibilidade dos microminerais de fonte orgânica, uma vez que não houve comprometimento dos parâmetros de desempenho produtivo das poedeiras e, ao mesmo tempo, observaram-se melhorias na deposição mineral, aumento no percentual de cálcio e diminuição no número de poros. Contudo, não houve alteração da espessura da casca, nos tratamentos com níveis de inclusão menores que o controle. De acordo Miles \& Henry et al. ${ }^{(15)}$, os minerais quelatados podem ser considerados mais biodisponíveis por diminuir a ocorrência de reações químicas indesejáveis no trato gastrointestinal ou por serem melhor absorvidos nas vias de absorção das moléculas orgânicas.

Os microminerais orgânicos proporcionam aumento da atividade enzimática, maior retenção ${ }^{(14)} \mathrm{e}$ menor excreção mineral mesmo quando suplementados em dietas de poedeiras em níveis menores que os praticados para a inclusão de microminerais de fonte inorgânica. Isso determina melhorias na vida útil das aves, já que o excesso de inclusão de microminerais pode ser prejudicial por aumentar a excreção e favorecer a ocorrência de interações do microminerais entre si e outros compostos de igual importância para o metabolismo da poedeira, desempenho produtivo e qualidade de ovos.

Aquase totalidade dos trabalhos encontrados na literatura avalia a influência da inclusão de microminerais orgânicos à dieta das poedeiras sobre a qualidade interna dos ovos pela determinação das unidades Haugh. No entanto, os resultados obtidos no presente trabalho demonstraram que, ao mesmo tempo em que houve aumento no percentual de matéria mineral dos ovos, ocorreu diminuição no teor de proteína bruta de albúmen e gema, deixando clara a necessidade de realização de análises bromatológicas para o acompanhamento do percentual dos principais componentes dos ovos.

Há necessidade de mais investigação sobre a suplementação de microminerais de fonte orgânica na dieta das poedeiras para se determinar o nível de inclusão ideal para promover a melhoria na qualidade externa sem comprometimento na qualidade interna dos ovos e desempenho produtivo das aves.

\section{Conclusão}

Os microminerais de fonte orgânica, quelatados a aminoácidos, podem ser utilizados em substituição a fonte inorgânica de minerais, em níveis reduzidos em até 70\%, à suplementação da dieta sem alterar o desempenho zootécnico das poedeiras e proporcionando melhorias na qualidade de casca.

COMITÊ DE ÉTICA E BIOSSEGURANÇA: Análise no 131/10. Protocolo de autorização da Comissão de Ética na Utilização de Animais - CEUA/UFU 073/10.

\section{Referências}

1. Vieira SL. Chelated minerals for poultry. Brazilian Journal of Poultry Science. 2008;10(2): 73-79. 
2. Mabe IC, Rapp M, Bain M, Nys Y. Supplementation of a corn-soybean meal diet with manganese, copper, and zinc from organic or inorganic sources improves eggshell quality in aged laying hens. Poultry Science [Internet]. $2003 \mathrm{Jul}$ [cited $2012 \mathrm{Fev}$ 3];82(12):1903-1913. Available from: http://ps.oxfordjournals.org/ content/82/12/1903.full.pdf

3. Swiatkiewicz,S, Koreleski J. The effect of zinc and manganese source in the diet for laying hens on eggshell and bones quality.VeterinarniMedicina [Internet] 2008 [cited Mai 2012);53(10):555-563. Available from: http://www.vri.cz/docs/vetmed/53-10-555.pdf

4. Uauy R, Olivares M, Gonzalez M. Essentiality of copper in humans. The American Journal of Clinical Nutrition [Internet] 1998 May [cited Jul 2012];67 (suppl.): 952-959. Available from: http://ajcn.nutrition.org/ content/67/5/952S.full.pdf + html

5. Scheideler SE. Trace minerals balance in poultry. World's Poultry Journal [Internet] 2008 Dec 01 [cited Jun 2012] Available from: http://www.zootecnicainternational.com/article-archive/nutrition/284-trace-mineralbalance-in-poultry.html

6. Baumgartner SDJ, Brown E, Salevsky JR, Leach RM. Copper deficiency in the laying hen. The Journal Nutrition [Internet] 1978 [cited May 2012];108:804-811. Available from: http://jn.nutrition.org/content/108/5/804.full. pdf

7Andrews NC. Metal transporters and disease. Current Opinion in Chemical Biology 2002;6(2):181-186.

8 Hamilton RGM. Methods and factors that affect the measurement of egg shell quality. Poultry Science. 1982;61(10):2022-2039.

9. Peebles ED, Brake J. Relationship of egg shell to stage of embryonic development in broiler breeders. Poultry Science. 1985;64(12):2388-2391.

10. Fernandes JIM, Murakami AE, Sakamoto MI, Souza LMG, Malaguido A, Martins EN. Effects of organic mineral dietary supplementation on production performance and egg quality of white layers. Brazilian Journal of Poultry Science [Internet\} 2008 Jan/Mar [cited Jun 2012];10(1):59-65. Available from: http://www.scielo. br/pdf/rbca/v10n1/a09v10n1.pdf

11. Scottá BA, Vieira RA, Gomide APC, Campos PF, Barroca CC, Formigoni AS. Influência dos minerais quelatados e inorgânicos no metabolismo, desempenho, qualidade da carcaça e da carne de frangos de corte. Publicações em Medicina Veterinária e Zootecnia. 2014;8(9):975-1135.

12. Dobrzanski Z, Korczynski M, Chojnacka K, Górecki H, Opalinski S. Influence of organic of copper, manganese and iron on bioaccumulation of these metals and zinc in laying hens. Journal Elementol [Internet] 2008 [cited July 2012];13(3):309-319. Available from: http:/www.uwm.edu.pl/jold/poj1332008/jurnal-03.pdf

13. Saldanha ESPB, Garcia EA, Pizzolante CC, Faittarone BG, Sechinato A, Molino AB, Laganá C. Effect of organic mineral supplementation on the egg quality of semi-heavy layers in their second cycle of lay. Brazilian Journal of Poultry Science [Internet] Oct/Dec 2009 [cited May 2012];11(4): 241-247. Available from: http:// www.scielo.br/pdf/rbca/v11n4/v11n4a5.pdf

14. Sun Q, Guo Y, Li J, Zhang T, Wen J. Effects of methionine hydroxy analog chelated cu/mn/zn on laying performance, egg quality, enzyme activity and mineral retention of laying hens. Journal of Poultry Science [Internet] 2012 [cited June 2012];49:20-25. Available from: https://www.jstage.jst.go.jp/article/ jpsa/49/1/49 011055/_pdf

15. Miles RD, Henry EPR. Relative trace mineral bioavailability. Ciência Animal Brasileira. 2000;1(2):73-93 